\title{
La Representaciones Sociales: Teoría, Evolución y Aplicabilidad: Una Mirada desde la Praxeología
}

\author{
Natalia Caraballo Noriega ${ }^{1}$ \\ Javier Prieto ${ }^{2}$
}

\section{Resumen}

El propósito de este artículo es realizar una revisión de la teoría de las representaciones sociales, diversos autores que han desarrollado el tema, su evolución y aplicabilidad en diversas áreas de conocimiento. Se hace un acercamiento a esta teoría a través de una búsqueda bibliográfica en plataformas como WOS (Web of Science) y Scopus, decantando por temas, autores y año de publicación, esto como un intento para ubicar un escenario de difusión para esta teoría. Finalmente, se hacen conclusiones sobre perspectiva general de la revisión y el estado de desarrollo.

\section{Palabras Claves}

Representaciones sociales, aplicabilidad, psicología, sociología, management, branding.

\begin{abstract}
The purpose of this article is to review the theory of social representations, various authors who have developed the topic, its evolution and applicability in different areas of knowledge. An approach to this theory is made through a bibliographic search in platforms such as WOS (Web of Science) and Scopus, decanting by themes, authors and year of publication, this as an attempt to locate a dissemination scenario for this theory. Finally, conclusions about the general perspective of the review and the state of development are made.
\end{abstract}

\section{Keywords}

Social representations, applicability, psychology, sociology, management, branding.

1.Especialista en Gestión Gerencial, Administradora de Empresas, Universidad de Cartagena; Joven Investigadora Colciencias - 2017. Contacto: natalia17_78@hotmail.com

2. Economista, Universidad de Cartagena 


\section{Introducción}

El presente artículo pretende mostrar de forma sistemática aspectos clave sobre la teoría de las representaciones sociales, diversos autores y sus aportes, evolución de la misma y la aplicabilidad teórica en aspectos de negocios, gestión administrativa, branding e innovación, es así, que través de una búsqueda en la base de datos WOS (Web Of Science) se hace una búsqueda por tema teniendo en cuenta las palabras claves "social representations", de esta búsqueda detallada realizada en Octubre de 2018, se obtiene un resultado de 2.306 artículos que se comprenden entre los años de 2014 al 2018, los cuales tratan las representaciones sociales como una herramienta para explicar fenómenos de diversas áreas como son los negocios, gestión administrativa, psicología, religión, leyes, geografía, arte, entre otras. La mayoría de los documentos se relacionan directamente con temas de psicología que equivalen al $17 \%$ del total de los resultados, asimismo se tiene que un $7 \%$ de estos se relacionan con la aplicación de las representaciones sociales en el área de Sociología, seguidamente un $4 \%$ equivale a documentos que enlazan las comunicaciones con la teoría de las representaciones sociales y un $2 \%$ con negocios y gestión administrativa.

Paralelamente se hace una búsqueda de información en la base datos de SCOPUS donde al escribir las palabras claves de "social representations" se presentan un total de 3.896 resultados compuesto por documentos como artículos, revisiones, resúmenes de conferencias y artículos para la prensa, cabe resaltar que estos documentos se han publicado desde 2014 hasta el 2018. Seguido a un proceso de filtrado se tiene que un $46 \%$ corresponde a documentos que tratan las representaciones sociales enmarcados en temas de las ciencias sociales, un 34\% corresponde a temas de psicología y un 5\% son los que relacionan las RS con los negocios, Gestión administrativa y contabilidad. Este último será el centro de acción de este artículo precisamente para reconocer la aplicabilidad de la teoría, reconocer su versatilidad y la utilidad de acuerdo a la finalidad del autor para abordar el objeto de estudio, en definitiva, se presentarán conclusio- nes sobre los aspectos relevantes encontrados, puntos en común y aportes presentados.

\section{Ilustración 1 Distribución de documentos por áreas de conocimiento según WOS}

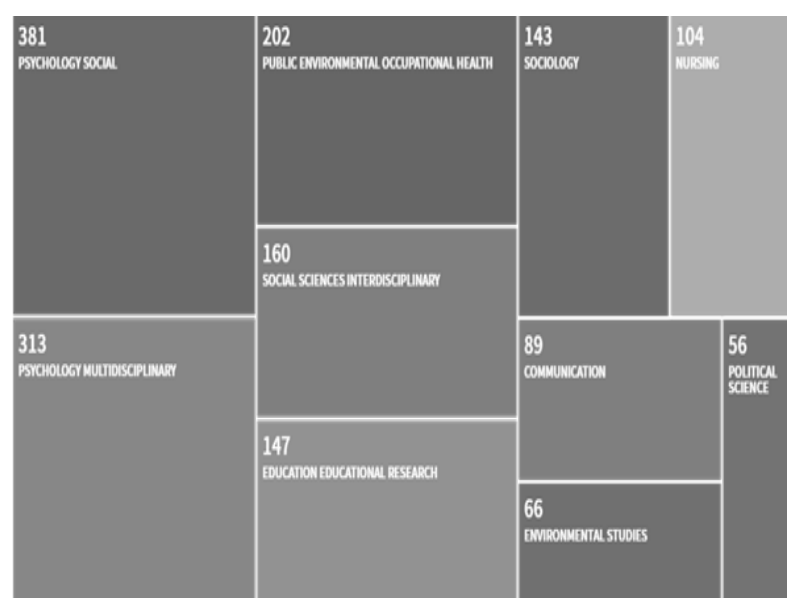

Fuente: Elaboración propia

\section{Representaciones sociales}

El estudio de la teoría de las representaciones sociales ha sido clave para abordar diversos fenómenos desde la interdisciplinariedad y como medio para tratar de responder a las necesidades de los autores, bien sea para dar una perspectiva epistemológica de la teoría en sí, revelar la influencia de un pensamiento grupal en la percepción de la realidad o en la forma como un fenómeno es percibido de forma colectiva, autores como (Bonetto, 2018) aborda las representaciones sociales como una teoría que se construye de una realidad social y necesidades afiliativas. Esta teoría tiene una estructura cuyo significado se fortalece para los individuos de una sociedad consolidados en objetos y símbolos, de igual forma, tiene en cuenta la relación entre la perspectiva de los individuos y del colectivo para entender la realidad, esta perspectiva hace ver a los individuos como una "especie" desde el punto de vista biológico y psicológico, esto como característica esencial para las manifestaciones de la mente individual y su pertenencia con un colectivo.

De acuerdo a este estudio las representaciones sociales surgen en las comunidades como una dinámica de selección natural que integra una perspectiva revolucionaria para abordar la con- 
cepción y términos indispensables para el pensamiento y las necesidades humanas. Esta dinámica es precisamente la de dar un significado al entorno, en otras palabras, es más una perspectiva moderna alejada de la contribución del debate del renacimiento y de la cognición epistemológica de la parte social, en otras palabras, no es más que una visión que permite la construcción de enlaces con otras teorías para significación de la realidad social y que estén a favor de las conexiones teóricas y metodológicas.

Como se ha dicho la relación de los individuos con la realidad social es fundamental para consolidar una teoría de las representaciones sociales, en otros estudios como en el de (Federico, Galli, Fasanelli, \& Schember, 2017) se expresa que la dinámica de dar significado a la realidad está ligada con los símbolos y conceptos que se desarrollan dentro de un colectivo, lo que se conoce como cultura, es así, que estos autores explican que las RS dan sentido a la cultura a medida que las personas piensan teniendo en cuenta el lugar donde se desenvuelven. Esto es la mejor vía para entender el porqué y el cómo se piensa en relación al mundo que nos rodea empezando por el entorno más próximo.

Se continúa con la búsqueda de información para ampliar el concepto de representación social, es así que según diversas perspectivas se evidencia una nueva visión en relación a la comprensión de la realidad y la cultura para estudiar la historia de los colectivos y la composición de un pensamiento, (Liu \& Hilton, 2005) analizan las representaciones sociales como una realidad social que legitimiza los acuerdos políticos y sociales de una comunidad, esta connotación es particularmente útil para definir los grupos sociales, por ejemplo, en las sociedades se pueden identificar mediante las RS a los ricos, los mecánicos, mujeres y según nacionalidad Europeos, Americanos o Africanos. Las RS describen la historia de las comunidades con elementos descriptivos estos incluyen eventos, sucesos democráticos, entre otros., por otra parte, esta teoría facilita a las comunidades establecer la normatividad y elementos constitutivos de los grupos sociales, en otras palabras, no es más que las reglas, normas, códigos morales, leyes sobre lo que se puede hacer y lo que no.

Ediciones EFIM
Las representaciones sociales permiten expandir el análisis social en diferentes vías, el componente descriptivo de la misma admite que un colectivo no solo está compuesto de estereotipos sino también de una narrativa explicativa, que muestra una guía para responder a las situaciones presentes, en definitiva, las RS permiten en una sociedad determinar los roles de villanos, héroes, legitimar actos y sentenciar políticas. Teniendo en cuenta los aportes señalados anteriormente sobre las RS es claro que es tema central para abordar diversas temáticas por lo que revistas a nivel internacional han publicado un sinnúmero de artículos científicos que la abordan, en este sentido las RS se vislumbran como una forma de entender la realidad, códigos y símbolos, de este perspectiva se destacan autores como (Joffe, 2003) quien se refiere a la conceptualización de RS en torno a los paradigmas sociales que se dan cuando se pretende entender el entorno, centrándose en los factores que van más allá de los procesos de información individual, se toma como referente el concepto de riesgo que se comprende en cada uno de los colectivos que contienen los pensamientos escépticos de las personas.

La teoría de las representaciones sociales toma un mapa de procesos que incluye aspectos socio-culturales, históricos y fuerzas específicas que se convierten en los sedimentos de las experiencias particulares propias, es decir, los plurales responden a los individuales, éstas emergen de una interpretación de eventos consensuados en relación a un fenómeno específicamente de las relaciones sociales. Como se mencionó anteriormente (Joffe, 2003) hace énfasis en las RS como una forma de comprender cómo se experimenta colectivamente el riesgo a situaciones de peligro por parte de las personas, el autor enfoca su trabajo a la contribución de las RS para percibir nuevos eventos que sean de riesgo para el ser humano en su colectividad, que específicamente se enfocan a salud, biotecnología, problemas mentales, los roles del ser humano en la sociedad y los procesos intrapersonales. Se puede afirmar que esta orientación de la teoría es de forma psicodinámica para dar una postura ante los potenciales peligros que operan en torno a la ansiedad afectando a una sociedad en 
general, en otras palabras, las personas según su representación de mecanismos de defensa que generalmente se asocian a los sentimientos y experiencias en riesgos.

(Bauer \& Gaskell, 2008) a diferencia de los otros autores mencionados en este artículo estos se centran más en la historia del estudio de las $\mathrm{RS}$ en relación a los avances en psicoanálisis de los años 50's en la sociedad francesa que empíricamente muestran la comunicación como un proceso en constante cambio, que involucra tener dificultades, intuición, metáforas y críticas para su formación. Los autores toman las anotaciones de Durkheim para expresar el pensamiento colectivo en los que la distorsión y la difusión son ejemplos claros de RS, esto conlleva a pensar en las ideas que surgen de los procesos comunicacionales y lo que sucede cuando estas ideas se comparten en un contexto particular por un grupo, es por esto que de acuerdo al pensamiento de la comunidad francesa en los años 50 se divide el psicoanálisis en un colectivo liberal de la zona urbana con opiniones escépticas basados en la asimilación de un contexto católico y otra parte con estereotipos comunistas que van en contra de las ideologías planteadas a la fecha, en otras palabras las representaciones se consolidan como una resistencia a lo que la sociedad determina. Por otra parte, las RS de acuerdo a estos autores, es una teoría de las dinámicas y representaciones del sentido común, sin dejar de lado la relación de la ciencia como fuente para generar conocimiento, en definitiva, "la forma en que se desarrolla la teoría, proporciona orientación sobre la conducción de la investigación empírica y despliega poderes sintéticos tanto dentro de la psicología social como a través de otras disciplinas, satisface los criterios que demarcan un programa de investigación "progresivo"”" (Bauer \& Gaskell, 2008).

En torno a esta revisión sobre la teoría de las RS, se encuentra que (Castro, 2006) hace un paralelo entre las representaciones sociales y los estudios teóricos sobre los problemas ambientales, en este se mira la evolución teórica desde que Moscovici en el lapso de 1961 a 1976 estudia la difusión de las ideas psicoanalíticas desarrolladas en Francia en los años 50, la cual toma fuerza en los 80 con la consolidación como una psicología social, en esta década la aplicación no fue clara y más adelante se da la clarificación de la perspectiva del espacio social y el conocimiento psicológico, una de estas aclaraciones está ligada a la relación entre sujeto y objeto en el que el conocimiento se construye de forma colaborativa, todo esto con el fin de defender la imperante relación entre las fuentes culturales, el lenguaje y la comunicación.

(Elcheroth, Doise, \& Reicher, 2011) afirman que las RS no son solamente es la forma de entender la cultura, el contexto y la realidad social, sino que constituyen en sí la realidad social y que en algunas ocasiones éstas cambian la naturaleza de nuestra realidad. Las RS organizan las prácticas sociales que nos consolidan en actores del campo político/social, éstas determinan las formas de actuar que son imaginables e inimaginables, bien decía el político conservador Británico Rab Butler que la política es el arte de lo posible, entonces las RS dibujan las fronteras de lo posible. En este estudio se concluye que las RS son una nueva forma de ver la realidad política, cabe resaltar que esto no es completamente nuevo pero es una invitación a que esta teoría se centre en un análisis de la psicología política y en segundo lugar, integrar consistentemente las formas para estudiar el fenómeno político-social.

Desde otra perspectiva, (Moloney, Hayman, Gamble, Smith, \& Hall, 2017) ofrecen información sobre las RS en cuanto a un marco de investigación para diversos autores que le dan sentido a temas complejos, nuevos o problemáticas del entorno, todo esto enfocado desde temas sociales a temas científicos o de salud. Asimismo, se afirma que las RS tienen su origen en la discusión e interacción entre individuos, esto sin dejar de lado las experiencias particulares de los hombres precisamente por la importancia de dicho pensamiento individual para ilustrar sobre la sinergia que da origen a un pensamiento colectivo. Se resalta que las RS son una teoría constructivista, en la que los individuos y los grupos sociales crean la realidad en la que se discute y comparte una realidad tanto para las representaciones sociales de objeto como para las representaciones del objeto social.

Anfibios ISSN: 2665-1513 
Tabla 1. Autores abordados a lo largo del artículo.

\begin{tabular}{|c|c|c|c|c|}
\hline Nombre Artículo & Autor & Fecha & Método & Aporte a la teoría \\
\hline $\begin{array}{l}\text { Risk: from perception to social } \\
\text { representation }\end{array}$ & $\begin{array}{l}\text { (Joffe, } \\
\text { 2003) }\end{array}$ & 2003 & $\begin{array}{l}\text { Revisión bibliográfica de diferen- } \\
\text { tes artículos sobre riesgo, sentido } \\
\text { común, representaciones sociales y } \\
\text { psicología. }\end{array}$ & $\begin{array}{l}\text { Aporta un enfoque en el que las RS muestran } \\
\text { una fuerte crítica a la percepción del riesgo, } \\
\text { debido a que en ocasiones dichas percepcio- } \\
\text { nes son erróneas para las personas. En otras } \\
\text { palabras a través de las RS se e han direcciona- } \\
\text { do hacia la comprensión del sentido común de } \\
\text { los individuos y las estructuras de significado } \\
\text { para ellos. } \\
\text { De igual forma, las RS aportan un método que } \\
\text { ayuda a comprender los factores contextuales } \\
\text { que alimentan el pensamiento del hombre. }\end{array}$ \\
\hline $\begin{array}{l}\text { The British Psychological } \\
\text { Society How the past weighs on } \\
\text { the present : Social representa- } \\
\text { tions of history and their role in } \\
\text { identity politics }\end{array}$ & $\begin{array}{l}\text { (Liu \& } \\
\text { Hilton, } \\
\text { 2005) }\end{array}$ & 2005 & $\begin{array}{l}\text { Estudio de los diferentes grupos } \\
\text { con impacto significativo en el } \\
\text { sentido de identidad y nuevos retos } \\
\text { para el presente. Realización de } \\
\text { encuestas, revisión de políticas e } \\
\text { historia en general. }\end{array}$ & $\begin{array}{l}\text { Las RS aportan una legitimización del social y } \\
\text { a los acuerdos políticos, estos ayudan a definir } \\
\text { grupos sociales. En otras palabras, las RS tie- } \\
\text { nen componentes descriptivos que san claridad } \\
\text { a los símbolos ligados a la sociedad. }\end{array}$ \\
\hline $\begin{array}{l}\text { Applying social psychology to } \\
\text { the study of environmental con- } \\
\text { cern and environmental world- } \\
\text { views: contributions from the } \\
\text { social representations approach. }\end{array}$ & $\begin{array}{l}\text { (Castro, } \\
2006)\end{array}$ & 2006 & $\begin{array}{l}\text { Investigación metodológica sobre } \\
\text { problemas ambientales desde los } \\
\text { años } 70 \text {, articulación de varia- } \\
\text { bles socio-culturales en la forma } \\
\text { de crear representaciones y la } \\
\text { consistencia teórica de los cambios } \\
\text { ambientales. }\end{array}$ & $\begin{array}{l}\text { Las RS son una parte molar relacionada con los } \\
\text { sistemas políticos de los individuos y colecti- } \\
\text { vos, El enfoque de representación social ayuda } \\
\text { a mostrar cómo los estudios sobre la preocu- } \\
\text { pación ambiental puede beneficiarse de: (1) la } \\
\text { aclaración de los conceptos que guían la inves- } \\
\text { tigación, la ampliación de los niveles de análisis } \\
\text { abordados, y una estrategia de triangulación en }\end{array}$ \\
\hline $\begin{array}{l}\text { Social representations theory: A } \\
\text { progressive research programme } \\
\text { for social psychology }\end{array}$ & $\begin{array}{l}\text { (Bauer } \\
\& \\
\text { Gaskell, } \\
2008)\end{array}$ & 2008 & $\begin{array}{l}\text { Revisión bibliográfica del concepto } \\
\text { de representación social, sentido } \\
\text { común, segmentación social, psico- } \\
\text { logía social. }\end{array}$ & $\begin{array}{l}\text { Las RS en relación a los avances en psicoaná- } \\
\text { lisis de los años } 50 \text { 's en la sociedad francesa } \\
\text { que empíricamente muestran la comunicación } \\
\text { como un proceso en constante cambio, que in- } \\
\text { volucra tener dificultades, intuición, metáforas } \\
\text { y críticas para su formación. }\end{array}$ \\
\hline $\begin{array}{l}\text { On the knowledge of politics and } \\
\text { the politics of knowledge: How } \\
\text { a social representations approach } \\
\text { helps us rethink the subject of } \\
\text { political psychology }\end{array}$ & $\begin{array}{l}\text { (Elche- } \\
\text { roth } \\
\text { et al., } \\
2011)\end{array}$ & 2011 & $\begin{array}{l}\text { Repaso de la teoría a través de } \\
\text { conceptos como conocimiento } \\
\text { compartido, poder, realidad social, } \\
\text { meta conocimiento y comunica- } \\
\text { ción. }\end{array}$ & $\begin{array}{l}\text { Las RS no son solamente la forma de entender } \\
\text { la cultura, el contexto y la realidad social sino } \\
\text { que constituyen en sí la realidad social y que en } \\
\text { algunas ocasiones estas cambian la naturaleza } \\
\text { de nuestra realidad. Las RS organizan las prác- } \\
\text { ticas sociales que nos consolidan en actores } \\
\text { del campo político/social. Estas determinan } \\
\text { las formas de actuar que son imaginables e } \\
\text { inimaginables, bien decía el político conserva- } \\
\text { dor Británico Rab Butler que la política es el } \\
\text { arte de lo posible, entonces las RS dibujaban las } \\
\text { fronteras de lo posible. }\end{array}$ \\
\hline $\begin{array}{l}\text { The construction of icons as a } \\
\text { means of access to the social } \\
\text { representation of culture }\end{array}$ & $\begin{array}{l}\text { (Fe- } \\
\text { derico } \\
\text { et al., } \\
2017)\end{array}$ & 2017 & $\begin{array}{l}\text { Entrevista a } 620 \text { estudiantes para } \\
\text { reconocer la idea homogénea de } \\
\text { cultura. }\end{array}$ & $\begin{array}{l}\text { Las RS dan sentido a la cultura como esa forma } \\
\text { en que las personas piensan teniendo en cuenta } \\
\text { el lugar donde se desenvuelven. Esto es la } \\
\text { mejor vía para entender el porqué y el cómo } \\
\text { se piensa en relación al mundo que nos rodea } \\
\text { empezando por el entorno más próximo. }\end{array}$ \\
\hline $\begin{array}{l}\text { Translation strategies, contra- } \\
\text { diction, and the theory of social } \\
\text { representations: Why discussing } \\
\text { needles may improve blood } \\
\text { donor retention. }\end{array}$ & $\begin{array}{l}\text { (Mo- } \\
\text { loney } \\
\text { et al., } \\
2017 \text { ) }\end{array}$ & 2017 & $\begin{array}{l}\text { Encuesta online aplicada a una } \\
\text { muestra de } 703 \text { residentes de Aus- } \\
\text { tralia para reconocer las represen- } \\
\text { taciones sobre las dimensiones de } \\
\text { la donación de sangre. }\end{array}$ & $\begin{array}{l}\text { Las RS en cuanto a un marco de investigación } \\
\text { para diversos autores que le dan sentido a } \\
\text { temas complejos, nuevos o problemáticas del } \\
\text { entorno, todo esto enfocado desde temas so- } \\
\text { ciales a temas científicos o de salud. Asimismo, } \\
\text { se afirma que las RS tienen su origen en la } \\
\text { discusión e interacción entre individuos, esto } \\
\text { sin dejar de lado las experiencias particulares } \\
\text { de los hombres precisamente por la impor- } \\
\text { tancia de dicho pensamiento individual para } \\
\text { ilustrar sobre la sinergia que da origen a un } \\
\text { pensamiento colectivo }\end{array}$ \\
\hline
\end{tabular}

\section{Fuente: Elaboración propia}




\section{Evolución de la teoría de las Representacio- nes Sociales}

Habiendo analizado diferentes perspectivas sobre la teoría de las representaciones sociales y cómo los autores abordan y desarrollan la teoría, se hace necesario saber cómo ha sido la evolución de la misma en las diferentes áreas de conocimiento, bien sea en Psicología, Ciencias Sociales, Administración y Negocios. Seguidamente se encontrará a detalle los hallazgos para cada área según las bases de datos de WOS (Web of Science).

\section{Evolución teórica de las RS en Psicología}

De los 2.306 documentos, 382 corresponden a artículos relacionados con Psicología en sus ramas sociales, teóricas e interdisciplinarias centrándose en la historia de las sociedades y cómo a través de las RS se reconoce el legado de determinados actos en la antigüedad, la percepción de las comunidades sobre temas sociales como la discriminación, colonización y la posición social de cada grupo de personas. Ahora bien, se hace una descripción detallada de varios autores de esta área en relación a las RS y su aporte para la evolución de la misma.

Durante esta búsqueda el patrón clave es abordar las RS como una parte de la psicología social que pretende explicar el pensamiento compartido de un grupo de personas que se han enfrentado a un fenómeno social, es así que (Licata et al., 2017) se enfocan en analizar el Colonialismo en África y Europa desde el siglo XVI hasta el siglo XX, por lo que se tiene en cuenta la influencia de este proceso en la identidad de las personas colonizadas y de los que entraron a conocer aspectos sobre dicha colonización, por esto, se hace una investigación tomando una muestra de 1.134 estudiantes universitarios de tres países europeos y de seis africanos para conocer las Representaciones sociales de la estructura alrededor de la cultura tanto europea como africana, asimismo, saber si las representaciones sociales del colonialismo fueron mejor asimiladas por los europeos o por los africanos, la consideración de negativo o positivo por am- bas partes y las expectativas de ambos grupos sociales para procesos de reparación ante los daños ocasionados.

Continuando con lo anterior, la teoría de las RS evoluciona hacia un plano social en el momento que explica un proceso histórico como es el colonialismo, exponiendo que este se estructura cruzando dos dimensiones octogonales, una que está ligada a la explotación y abuso impuesto por las personas líderes de la colonización y otra en el desarrollo de infraestructura física y procesos educativos que trajo consigo el pueblo europeo a territorios como Angola, Cabo verde, Burundi, República Popular del Congo y Mozambique. Ante los estudios realizados se tiene que a través de la teoría de las $\mathrm{RS}$ se conoce la percepción del proceso de colonización en territorios africanos y se observa que los adultos asumen este proceso como una vía para el desarrollo en la civilización, desarrollo de infraestructuras y educación, mientras que las generaciones más jóvenes tienen una imagen en la que lo imperante fue el racismo, explotación y precarios servicios de salud, trabajo forzado y abuso moral, finalmente los de mediana edad incluyen en sus representaciones una mezcla de ambos aspectos mencionados anteriormente.

En definitiva, con las RS se logra validar la bi-dimensionalidad de la estructura del colonialismo para diversos grupos sociales, se hace un paralelo entre la explotación y el desarrollo que hubo a raíz de este proceso, por otra parte, se destaca que los jóvenes a pesar de tener los mismos rangos de edad pueden tener representaciones diferentes como fue en el caso de los jóvenes europeos que perciben la colonización como negativa y los africanos lo representan como algo no del todo negativo sino que también trajo consigo otros aspectos más positivos. Las RS para este caso están conectadas con la identidad nacional.

Como es claro la teoría de las RS sirve como herramienta para entender fenómenos sociales y es abordado desde la mirada de Psicología Social por (Kadianaki \& Andreouli, 2015) quienes hacen este tipo de análisis para conocer las esencialidades en relación a las Representaciones Sociales de la ciudadanía desde la mirada de Anfibios ISSN: 2665-1513 
ciudadanos griegos y migrantes. Ante la legislación sobre la ciudadanía griega se hace un estudio sobre las representaciones de ciudadanos y no ciudadanos griegos sobre esta normatividad, es así que se conceptualiza en primera instancia la ciudadanía como una categoría discursiva que sirve como fuente clave para la argumentación, también se afirma que la ciudadanía está ligada con los derechos de los migrantes, es decir, entender la ciudadanía también es un significado simbólico de las fuentes que van en contra de la inclusión de migrantes.

En segundo lugar, se hace una definición del objetivo del trabajo el cual es saber la contribución de la psicología desde una perspectiva empírica y teórica, desde esta última las RS se constituyen como un complemento para aportar una visión política y psicológica de la ciudadanía, dicho de otra manera, la dimensión política implica tener claro conceptos como esencialismo para hacer viable una representación. Las Representaciones como sistema de conocimiento permiten a las personas construir un significado para el conocimiento acerca del mundo social y de la posición de cada individuo. Con esto es claro que para construir significados los patrones de comunicación son importantes para actuar como mediadores sociales en la relación entre grupos.

En este sentido, la teoría pasa de ser una simple forma de explicar los fenómenos en un colectivo a ser más bien un parámetro comunicacional para entender las relaciones entre individuos y algunos aspectos de tema social que los impactan, de acuerdo al estudio anterior se concluye que el concepto de ciudadanía tiene una representación construida específicamente relacionada a los derechos de los migrantes, en un campo inexplorado la perspectiva de los migrantes es dualista y muestra un énfasis político que está enfocado al individuo más allá de una explicación psicológica. En definitiva, con la ayuda de las RS se identifica en la comunidad griega que la sociedad tiene presente siempre el origen étnico, el civismo y la participación ciudadana, la dicotomía de estos aspectos ha evolucionado para acentuarse en la cultura de la ciudadanía y las imágenes de la misma.

Ediciones EFIM
Como se ha dicho, las RS son útiles para dar explicación a la realidad y entender situaciones de tipo político y social, estas también facilitan conocer cómo está representado un concepto en la mente de un colectivo. Es así que (Greenland, Andreouli, Augoustinos, \& Taulke-Johnson, 2018) abordan mediante un estudio las representaciones la discriminación, para el que describen un contexto en el que para la mayoría de las personas el concepto de discriminación es negativo sin reconocer las fronteras entre discriminación y no discriminación, por este motivo se hace un estudio con entrevistas de tipo cualitativo y grupos focales con minorías con una muestra total de 54 personas divididas entre mayorías (heterosexuales y blancos) y minorías (negros, asiáticos y gais).

Ante esto es evidente que la evolución de la teoría es esencial para la comprensión de diversas situaciones sociales, como muestra (Lelaurain et al., 2018) abordan la violencia domestica a través de las RS, así como se ha tratado la discriminación, política, temas de ciudadanía, migración, abusos, historia y grupos étnicos, estos autores presentan una investigación que encaja con el concepto de representación social para analizar el impacto de las ideologías sobre la violencia entre parejas, se utiliza un método mixto en el que se hacen dos estudios en el primero intervienen 24 participantes a quienes se les pregunta sobre la violencia entre parejas y su perspectiva, paralelamente en un segundo estudio se cuestiona a 123 participantes sobre los resultados del primer estudio para evaluar la severidad y justificación de las representaciones sobre este fenómeno en la sociedad francesa específicamente.

Las Representaciones sociales ofrecen un marco heurístico psicológico para entender los hechos sobre la violencia de género, estas pueden definir los tipos de conocimientos que desarrollar la interacción social, los cuales tienen una finalidad práctica que lleva a construir la realidad común para un grupo. El aporte de este trabajo a la teoría es precisamente el de generar un referente sobre la realidad y los procesos de pensamiento que se dan diariamente en los que están envueltas las RS, este acercamiento 
socio-constructivista nos permite re-considerar los individuos y grupos como parte de un mundo de objetos que son analizados en relación a los otros, que es el corazón de las inscripciones sociales y los procesos de participación.

En este sentido, la evolución teórica permite para este estudio saber la lógica y significados para los diferentes grupos sociales en lo que concierne a la violencia de género, cómo estas representaciones guían la comunicación y las relaciones interpersonales entre los grupos, en otras palabras, cada grupo interpreta este fenómeno según su realidad, por ejemplo los hombres tienden a ignorar este tipo de situaciones más que las mujeres quienes quizás han sido víctima de algún tipo de violencia, de igual forma, las mujeres son más propensas a buscar ayuda para las víctimas que los hombres, por esto las RS permiten explicar las diferencias en lo que compete a creencias, normas y roles que definen asuntos de identidad.

Siguiendo con este recorrido sobre la evolución de la teoría de las RS en cada una de las áreas de conocimiento delimitadas en este artículo, a continuación se expresa la importancia de las RS en el área de las ciencias sociales y cómo su evolución teórica ha permitido conocer aspectos claves sobre la memoria colectiva, motivación de las personas, la identidad y actuaciones de acuerdo a determinados fenómenos.

\section{Evolución teórica de las RS en Ciencias So- ciales}

En la revisión temática sobre "Representaciones Sociales" se hace filtros por categorías según el tipo de artículo y el área de conocimiento, dentro de las categorías determinadas por Web of Science, se encuentra la de "Social Sciences" en la que se haya un total de 160 documentos que utilizan el concepto de RS para explicar ciertas situaciones sociales y evolucionar en cuanto al concepto de la misma y su utilidad. En primera instancia se tiene el artículo de (Koshkin, Abramov, Rozhina, \& Novikov, 2018) se estudia el papel de las RS en la motivación de los estudiantes para adquirir educación superior, teniendo en cuenta las representaciones de cada estudiante sobre la motivación y estrategias por parte de las universidades para retener a sus estudiantes a la vez que desarrollan metodologías para incentivar la realización de cursos vocacionales, en este sentido, se hace una encuesta a 452 estudiantes rusos en los que se analiza las representaciones sobre la educación superior teniendo en cuenta el contexto, condiciones y costo, representaciones sobre los requisitos para estudiar determinadas carreras profesionales, características y expectativas.

Es así que este trabajo aporta una perspectiva sobre la estructura de las RS, en la que se tiene en cuenta tres elementos como son la sensibilización de la información, campo de representación y afirmación. Todo esto para saber que en primera instancia las representaciones se forman con una sensibilización de la información para caracterizar contenidos según un material desde el punto de vista cualitativo, la representación expresa de forma general la actitud del sujeto sobre el objeto representado.

Dicho de otra manera, las RS se constituyen en el centro de la memoria colectiva de un grupo, se define a través de un consenso el cual es estable, coherente y sostenible, no es muy sensible al contexto actual, cumple la función de generación de nociones e identifica la estructura de la representación en sí misma. Con este estudio se puede reconocer el impacto de las RS en el comportamiento de los grupos y define las variables de actuación individual y colectiva, es decir, en las interacciones entre personas las RS determinan un potencial en el campo de comunicaciones, el valor de las ideas expresado desde diferentes puntos de vista y la función de orientación hacia funciones específicas.

Se destaca la contribución teórica para la generación de nuevas representaciones en el que el comportamiento no es unidireccional sino que se convierte en el insumo clave para nuevas representaciones en relación a algún fenómeno, a la vez que se reconstruye los elementos del mundo externo se va dando significado al comportamiento de los individuos. Continuando con los aportes de los estudios a la teoría de las RS, se hace un paralelo con la educación superior en el que se tiene presente los constantes Anfibios ISSN: 2665-1513 
cambios de las tecnologías y su influencia en las condiciones de trabajo, se percata de que a raíz de esto la sociedad contemporánea se encuentra confusa cobre que estudios realizar, las responsabilidades de estudiar y trabajar, asimismo el impacto en la identidad, y en que entre más alto nivel de estudio se podrá acceder a un mejor empleo, esto respaldado con cifras de estudios sociológicos en los que un $67 \%$ de los empleadores rusos dan más importancia a diplomas y certificados cuando eligen a un trabajador para sus compañías.

En definitiva, este estudio permite comparar las RS con otros factores que afectan las aspiraciones de las personas en relación a algún propósito, es específico las RS para la educación superior en estudiantes es más orientado a la educación vocacional como medio para adquirir certificados y diplomas en cursos avanzados enlazados a propósitos a largo plazo. Las representaciones tienen un aporte positivo para los estudiantes en torno a acciones para ser líderes universitarios y sus grados teniendo en cuenta motivaciones de costos, cultura y otros.

\section{Evolución teórica de las RS en Administra- ción y negocios}

De acuerdo a una búsqueda exhaustiva en Web of Science los resultados para artículos relacionados con Administración y negocios son claves para tratar temas como la apropiación de tecnologías en las empresas, análisis de las representaciones de estudiantes de negocios, nivel de satisfacción de clientes en relación al papel de las RS, en este sentido se abordan teóricamente estos documentos para reconocer cuál ha sido la evolución teórica de las RS en la explicación de diversas situaciones en el plano administrativo.

(Bartels \& Onwezen, 2014) se enfocan en la teoría de las RS para reconocer clientes y su identidad con relación a la comida orgánica y su incidencia en la compra de productos que afectan el ambiente, para lo que se hace un sondeo con 1.006 clientes del Reino Unido, el cual busca demostrar que como clientes estamos más ligados a las tecnologías de producción de alimentos que a la compra de productos que sean Ediciones EFIM amigables con el ambiente y que respeten las normas ética de protección de la salud.

Es claro para estos autores que las experiencias de los consumidores son variadas según sus necesidades, por ejemplo algunos consumidores ven la comida como una simple necesidad, otros la consideran como un punto importante de su vida, es así que a través de las RS se puede dar un significado a los productos e incidir en su proceso de compra, todo esto sabiendo que esta teoría se conoce como el sistema de valores, ideas, creencias y prácticas que se comparten entre individuos de un colectivo. Una nueva perspectiva sobre la teoría se ve evidenciada en este artículo en el que se tiene una aplicación a la comida en el que se evalúa la consideración de los consumidores sobre adherencia a la tecnología de producción, la procedencia natural de dichos alimentos, la necesidad de comer o la satisfacción de comer, todos estos aspectos claves para saber las dimensiones de la identidad con la comida y sus variedades y asimismo para estudiar la influencia de tendencias de cuidado ambiental en la selección y compra de determinados productos alimenticios.

Después de tener en cuenta dichas variables y la aplicabilidad de las RS, los resultados muestran la relación entre la adherencia a productos naturales y el cuidado ambiental y de la salud, en otras palabras los consumidores tienen diferentes motivaciones para comprar un producto orgánico, y además está ligado a quienes consumen alimentos por satisfacción no desean comprar productos orgánicos ni mucho menos para ayudar al ambiente. En definitiva, con las representaciones sociales se percibe que la idea de comprar determinados productos es muy variada según las necesidades del consumidor, las edades y el ambiente en el que se desenvuelve.

Continuando con esta misma corriente se encuentra otro estudio en el que se analiza la percepción de los clientes sobre los diversos medios de pago según un análisis a través de las RS, (Penz \& Sinkovics, 2013) describen los sistemas sociales como prioritarios para dar forma a las necesidades de los clientes para comprar y pagar por sus productos, en este caso las RS permiten desenredar las fuentes de la actitud 
individual o diferencias y similitudes con los grupos sociales como referentes para identificar el comportamiento del consumidor, de igual forma se identifica el concepto abstracto de sistemas de pago en relación a objetos tangibles y el impacto social de los prototipos de pago que son innovadoras bien sea tarjetas de crédito, cajeros automáticos y tarjetas débito.

Las RS para este caso se analizan como una teoría que hace constructos sobre la existencia, relaciones sociales y la formación de conocimiento teniendo en cuenta la perspectiva del sentido común, así pues, esto refuerza la concepción sobre los productos y su asociación con nuevos productos, esto es para permitir una evaluación sobre productos en comparación con los pensamientos de grupos sociales que ajustan su pensamiento sobre las innovaciones del mercado.

Por otro lado, la exposición a los medios y la interacción con otros individuos ayuda a crear una percepción de consumidor que se posiciona en el plano familiar, especialmente de frente a las nuevas tendencias económicas, opiniones de expertos y comparación de opiniones con pares, en este contexto, la teoría de las RS golpea la ideal de intercambio social en Marketing. En suma, las RS son una forma amplia para reconocer las estructuras de consumo, el contexto social en el que los consumidores aprenden, percepciones y desarrollo de su visión en torno a una concepción teórica colectiva, aterrizado al estudio se puede conocer las ideas sobre las innovaciones para pagos y la integración con las formas tradicionales de pago.

Se analiza en este punto las RS más allá de una forma para explicar el comportamiento del consumidor en relación a determinados productos y las formas de pago, en este sentido se miran las RS como un nuevo concepto para explicar el pensamiento compartido que se consolida como sentido común, los autores (Schultes, Kollmayer, Mejeh, \& Spiel, 2018)empirical studies focusing on stakeholders' attitudes toward evaluation are scarce. The present paper explores the approach of assessing social representations as indicators of people's attitudes toward evaluation. In an exploratory study, two groups were surveyed: University students $(n=60$ hacen un análisis de los "grupos de interés" para las empresas a la luz de esta teoría, es así que se da un paso más sobre la teoría al describirla como un sistema de posiciones, opiniones y valores que se relacionan a un objeto social, dicho objeto social puede ser entendido de diversas formas por cada grupo social lo que es un desarrollo empírico de la teoría en el siglo XX, es decir, la evaluación de la sociedad se convierte en parte fundamental de la organización en variedad de campos lo que permite tener bases de comunicación y acción. En otras palabras, este documento se centra en conocer las representaciones sobre evaluación y puede que esta no este conforme a un concepto científico de la palabra "evaluación", precisamente por el rol determinante de las actitudes y relaciones de los grupos de interés en sus contextos sociales.

Estas representaciones se pueden estructurar en dos secciones que son el corazón y la periferia, el corazón representa las bases de la representación y que no cambian tan fácilmente como si lo hacen los elementos de la periferia, es así que entre más cambios tenga el corazón más cambiará la representación lo cual debe ser importante tener en cuenta para definir de forma organizacional a qué mercado enfocarse. Por estos motivos, existen métodos para evaluar las RS como son las entrevistas, análisis de contenido de diversas fuentes y análisis de libre asociación los cuales revelan las formas de pensar individualmente y la relevancia en un sistema social.

Como aporte de estos autores se tiene que las RS son vistas como indicadores de las posiciones, opiniones y valores de diferentes grupos sobre un concepto determinado, por lo que para el estudio es importante saber la percepción de evaluación aplicada a las organizaciones. En definitiva, con este estudio se pudo concluir que la evaluación se puede abordar desde la metodología de libre asociación como indicador de actitudes frente algo, y que especialmente la actitud de los "grupos de interés" toma importante lugar para evaluar procesos y dar mejores beneficios a determinados procesos.

Ante la necesidad de explicar las necesidades de un grupo en particular y cómo esto afecta a los negocios y la toma de decisiones en torno Anfibios ISSN: 2665-1513 
a productos y servicios ofrecidos, (Lai, Morrison-saunders, \& Grimstad, 2017) desde otra perspectiva toman las RS para explicar la operación de pequeñas empresas en el sector turístico en zonas rurales, se distingue entre la percepción de los gerentes de estas empresas y la motivación para obtener información de la población sobre los cambios de perspectiva del turismo y normatividad vigente sobre las necesidades del mercado en acomodación y estilos de vida.

A través de entrevistas a propietarios de establecimientos turísticos en Australia se examina las RS como una teoría en la que las personas se comprometen con la tarea de dar sentido común al mundo en el que se desenvuelven y comunicárselo a los demás, a la luz de esta teoría se comprende la realidad individual sin dejar de lado las representaciones colectivas, lo que se toma como referente para explicar los cambios en entornos rurales que se consolidan como retos existenciales para los gerentes y propietarios de sitios turísticos, es decir, se examina la dinámica de las RS para inducir al cambio cultural y de creencias sobre un objeto.

Como resultado de entrevistas a habitantes y gerentes de lugares de interés turístico en Gloucester se tiene que las RS sobre el lugar es que es reconocido por su ambiente natural y atractivo natural en cascadas, granjas y verdes pastos, sin embargo este destino en el que residen y operan sus negocios han sido influenciados por el turismo interfiriendo con dicha representación. Se revelan que muchos propietarios / gerentes se involucran en el sector del alojamiento principalmente motivado por objetivos de estilo de vida. Estos objetivos están estrechamente relacionados con lo que representa el destino como un lugar y lo que tiene para ofrecerles como residentes y propietarios / gerentes. El destino se representa principalmente como un paisaje natural y comunidad rural con las cualidades deseadas.

A través de las interacciones con el área por un período de tiempo, el área ha de convertirse en hogar de un sentido de apego al lugar, auto-identidad, y comunidad. Los cuatro temas que componen la representación servir como anclas para guiar la visión de los propietarios Ediciones EFIM y gerentes y expectativas para su negocio y el futuro desarrollo de la zona.

Aplicabilidad de las Representaciones Sociales Como es claro la evolución de la teoría de las RS ha sido acelerada y se centra en ampliar la concepción sobre principios, valores y conocimiento del entorno por parte de los individuos y la forma en que lo comparten dentro de un colectivo, es así que esta teoría ha dado pie a diferentes estudios en áreas sociales y de administración en los que se mira desde otra perspectiva la utilidad de la teoría para explicar determinados fenómenos, en definitiva, saber el pensamiento y percepción de un colectivo sobre una situación permite saber cómo actuar, las estrategias a determinar y los campos de acción para construir un mejor panorama que beneficie a todos.

En este sentido, a continuación se hace una recopilación de diferentes estudios para analizar la aplicabilidad de la teoría de las RS en campos de Innovación, Management y Branding. Se hace un filtro de documentos por categoría y dentro del campo denominado Management se encuentran un abordaje desde la aplicabilidad de las representaciones sociales para los estilos de consumo, la incidencia de la tecnología en las empresas y las vulnerabilidades del consumidor en relación a una coyuntura en particular.

\section{Aplicabilidad en Innovación}

Del total de artículos el de los autores (Levidow \& Upham, 2017) se centra en temas de Innovación y utilizan las RS junto a la perspectiva multinivel para mostrar cómo una nueva tecnología está "anclada" de manera diversa en la sociedad desde diferentes puntos de vista, específicamente se hace un estudio de la innovación en los tratamientos térmicos de residuos sólidos municipales dentro de un régimen amplio de "energía a partir de residuos" en el Reino Unido, esto se convierte claramente en una oportunidad para empresas gasificadoras para generar incineradores para dar jerarquía a los residuos. Es así que cada grupo de interés tiene una representación social y un criterio sobre los diferentes marcos socio-cognitivos en relación a esta novedad. 
Desde esta perspectiva las RS se analizan como una teoría socio-psicológica de la cognición que tiene una alta influencia social en la que los actores buscan entender lo desconocido para hacerlo "familiar", se intenta anclar las ideas extrañas para reducirlas a categorías e imágenes ordinarias para colocarlas en un contexto familiar. La familiaridad se busca de dos maneras complementarias. Primero, convencionalizar nuevos conceptos y darles un común reconocible, mejorando así la comunicación y la coordinación dentro de un grupo, en segundo lugar, las representaciones prescriben formas de percibir la novedad: "son obligados, transmitidos y son el producto de una secuencia completa de las elaboraciones y de los cambios que se producen en el transcurso del tiempo son el logro de generaciones sucesivas"(Mora, 2002).

Esta aplicabilidad permite evaluar las RS como dinámicas, cambian junto con nuevas ideas, esto por ejemplo en el campo de la tecnología en el que se centra este estudio especialmente de la fracturación hidráulica para el gas natural en el Reino Unido, en el que entra en juego la percepción de la industria petrolera, los defensores de estas prácticas innovadoras para generar empleos, la seguridad energética doméstica y la contaminación ambiental. Haciendo hincapié en lo anterior, las RS ayudan identificar los roles de los agentes socio-políticos en la promoción de las normas para cambios y transiciones en los procesos de explotación y manejo de desechos, es una invitación a clarificar las cuestiones generacionales sobre los agentes de cambio para tener un régimen sobre sustentabilidad y competencia e innovación tecnológica, en este caso los estudios brindan una perspectiva de las cuestiones teóricas determinan estrategias alrededor del marco de las RS que implican un compromiso de parte del gobierno del Reino Unido para reducir el volumen de desechos, mejorar la productividad energética y criticar las incineración sustancial.

\section{Aplicabilidad en Management}

A lo que respecta a la categoría de Management se aborda la administración en torno a la aplicación de las RS, como muestra (Visconti, 2016) hace un acercamiento a la vulnerabilidad de los consumidores, en el que se entiende que dicha vulnerabilidad se hace a través de la conversación e interacción entre actores para construir una posición en el mercado.

Mediante un estudio de performatividad, representaciones sociales como herramienta para revelar posiciones de poder y normatividad y de narración en el que se evidencian los mecanismos persuasivos y alternativos más poderosos para convencer a clientes a acceder a un producto y/o servicio se pretende reconocer las RS de las personas para revelar el verdadero poder de consumo y la normatividad vigente para cobijarlo, la aplicabilidad de esta teoría es clave para este caso porque se alinea con un análisis conversacional en vía de reconocer la visión social de los discursos u ambiciones de los actores que reproducen la normatividad de las organizaciones y de la realidad social. Asimismo, las RS muestran la vulnerabilidad más allá de las condiciones personales "objetivas" de los consumidores vulnerables (Género, edad, orientación sexual, subcultura de consumo), a través del poder de las normas, las RS son capaces de transformar las "interpretaciones" del mundo en “objetivación”.

Para este caso las RS sirven para una noble intención de hacer una imagen de la cultura y aspectos históricos que influyen en la consolidación de una idea sobre el consumo, es decir, estas van más allá para dar un significado ontológico y epistemológico sobre el mundo, en definitiva, los consumidores vulnerables y los grupos de mercado dominantes están comprometidos de manera contextual pero desigual como un efecto de sus diferentes posiciones de poder y las Representaciones responden a las necesidades de cumplir una obligación personal.

En suma, (Jung \& Pawlowski, 2014) aplican las RS para entender el comportamiento del consumidor pero en este caso a través de las redes y el ciberespacio, de igual forma, se busca identificar las representaciones de consumo virtual, para lo que se hace un estudio 154 participantes usuarios de "Second Life", en los que se idenAnfibios ISSN: 2665-1513 
tifican 32 conceptos y relaciones que muestran las percepciones colectivas del consumo virtual en un mundo social. Así pues, las representaciones sociales revelan los factores importantes de los usuarios de mundos virtuales y la economía virtual, hacen un acercamiento al sentido común de la organización cognitiva que se comparte entre los miembros de dichas comunidades.

En definitiva, se evidencia que a medida que avanza la tecnología los ciberespacios son más sofisticados, la interacción entre personas es más revolucionaria, atraen a personas para que desarrollen su propias plataformas y dispositivos para estar al tanto de actividades diversas y de más accesibilidad, lo que demuestra que aproximadamente 5.000 usuarios están en estas plataformas y el conocer sus estilos de consumo es un ingrediente importante para perpetuar su permanencia, aportar al desarrollo de actividades económicas dentro de estas plataformas que poco a poco van madurando y convirtiéndose en área importante de investigación.

\section{Aplicabilidad en Branding}

De acuerdo a la revisión adelantada en este artículo otro aspecto clave a destacar es la aplicabilidad de las RS en temas de Branding y su incidencia en comportamientos de consumo y desarrollo de plataformas acorde a las tendencias tecnológicas del mercado, (Rosa, Bocci, \& Picone, 2018) hacen un estudio de la imagen de las tarjetas de visitantes en Roma y París, las cuales surgen de la teoría de las RS en las que se compara la experiencia de las dimensiones del turista y ciudadano con la capitales históricas europeas, asimismo, se analiza el nuevo sistema comunicacional basado en las relaciones por Internet.

En este estudio se hace un análisis de uso, búsqueda en Atlas/ti para saber la identidad de los elementos que caracterizan las páginas web estudiadas como son la de Roma y París, se hace un recuento histórico de la evolución de estos sitios desde 2004 y la influencia de un software para mejorar aspectos de contenido, estructura, aspectos técnicos, perspectiva de objetos y funcionalidad. En conclusión, las representaciones Ediciones EFIM sobre estos sitios web era básicamente de poca objetividad, poca funcionalidad, debilidades en los parámetros y difícil para su navegación lo que permitió renovar el aspecto de los mismos para brindar una mejor experiencia, dar datos de ubicación, de miembros de las municipalidades y agregar una sección de búsqueda de empleo.

\section{Discusión}

La formación de conceptos para entender el entorno en el que nos desenvolvemos ha sido pilar de la ciencia para el desarrollo de disciplinas y teorías para tratar de dar una explicación acertada a los fenómenos que experimentamos, en este proceso de consolidación de una realidad en torno al pensamiento ha dado origen a formaciones socio-económicas demarcadas por patrones culturales y simbólicos compartidos que se conforman con creencias, costumbres, valores y referencias históricas consideradas como verdaderas, por esto, cada una de estas asociaciones son identificadas con modelos sociales que se comparten entre sus integrantes.

Por consiguiente, la identidad de las comunidades se desarrolla dejando ver las maneras de pensamiento, filosofías y caracteres en relación al entorno y el contexto en el que las personas se desenvuelven, esta identidad puede ser abordada desde una perspectiva de psicología experimental, social o discursiva para explicar el trasfondo de los símbolos, lenguaje e interacción social en la consolidación de la teoría de las representaciones sociales.

Como es claro, en este artículo se han revisado diferentes fuentes de información que toman como referente la teoría de las representaciones sociales para explicar fenómenos y situaciones de diferentes áreas del conocimiento como son las ciencias sociales, psicología, management, branding e innovación, de modo que se pueda entender el aporte a la forma en que los individuos perciben su entorno, cómo las representaciones e imágenes sobre algunos conceptos permite desarrollar estrategias, tomar decisiones o hacer cambios que se adapten a los conceptos familiares para los colectivos. 
Al analizar lo anterior se observa, que las representaciones sociales han permitido pasar momentos de crisis en los que no se podía explicar con un esquema de conocimiento determinado, el por qué las comunidades van consolidando pensamientos compartidos que forman una cultura caracterizada por símbolos, creencias y esquemas históricos aceptados. En este punto de la revisión es importante decir que no se tiene un concepto final para las representaciones sociales sino que más bien es un libro abierto donde cada disciplina puede aportar académicamente una dimensión sobre la cual abordar los fenómenos, cada estudio es una oportunidad para ahondar en la teoría y darle sentido a las situaciones, por ejemplo, a lo largo de este artículo las RS han facilitado los procesos de comprensión de comportamiento de consumidores, los patrones de acción de las personas en ambientes virtuales, la percepción sobre procesos de explotación de recursos y el impacto en el ambiente, conceptos negativos y positivos sobre normas, discriminación y procesos históricos que han marcado la cultura de las sociedades modernas, como resultado se resalta la función de las representaciones para dar forma y categoría a la realidad, la influencia que permite tener una comunicación con las personas y compartir dichos juicios y conceptos con los demás constituyendo una cultura representativa para cada uno de sus integrantes.

Haciendo hincapié en lo anterior, se miran puntos en común de los autores consultados y son precisamente en la relación del individuo con su entorno y las imágenes y símbolos que surgen de esta interacción que son compartidos en una sociedad que se constituyen como cultura, por otra parte, se converge en que las representaciones sociales han permitido discutir sobre el impacto de normativas en el pensamiento colectivo y cómo perciben las comunidades las decisiones gubernamentales para desarrollo de programas sociales.

Al mismo tiempo, los estudios consultados se enfocan en mostrar que las "imaginaciones" de los individuos son significantes y de alguna $\mathrm{u}$ otra forma aportan aspectos creativos de cada individuo con la finalidad de promover estilos de conducta, tipos de comunicación para generar un concepto sobre algo que se esté presentando. Como es claro, para que una representación surja los individuos deben valerse de la mucha o poca información que tengan y así focalizarse en algún aspecto claro que puede estar o no influenciado por la sociedad todo dependiendo de los objetivos de cada individuo.

En definitiva, de esta revisión sobre las representaciones se tiene que se constituyen como una herramienta para la interpretación de las culturas y las imágenes que tienen de su entorno, es la que permite comprenden determinados hechos o situaciones abordándolos de manera individual y colectiva.

\section{Conclusión}

Las representaciones sociales son sistemas cognitivos que tienen un lenguaje propio que va caracterizándose por una serie de símbolos e imágenes que van consolidando una representación por parte del individuo, van más allá de simples opiniones y se centran en una función básica del ser humano al ser "social".

Dicho de otra manera las representaciones permiten que el hombre tenga una función categorizan te de las relaciones sociales y emita pensamientos, conceptos y opiniones de aquellos fenómenos que se desarrollan en los colectivos que se encuentra. Todo esto en miras de descubrir su ordenación, sistemas de ideas, comportamientos para diseñar un código para sus intercambios entre sujeto-Objeto.

Se concluye para este proceso de representación social individual y colectivo se necesita una cantidad de información que en ocasiones puede ser abundante o escaza para que el individuo relaciones conceptos y emita juicios sobre determinados sucesos, asimismo, deben enfocarse en lo que tratan de entender y emitir una "opinión" sobre esto que es lo que va alimentando constantemente el conocimiento de las sociedades.

Anfibios ISSN: 2665-1513 
En definitiva, Las RS son el resumen de las experiencias de las comunidades y cómo perciben determinados conceptos bien sea familiares o no, la forma en que abstraen su realidad para explicar los fenómenos, es una herramienta clave para reconocer las imágenes de las personas y así adelantar estrategias, determinar puntos débiles y puntos de mejora en pro de un beneficio social y de desarrollo.

\section{Referencias bibliográficas}

Bartels, J., \& Onwezen, M. C. (2014). Consumers 'willingness to buy products with environmental and ethical claims : the roles of social representations and social identity. International Journal of Consumer Studies, 38, 82-89. https:// doi.org/10.1111/ijcs.12067

Bauer, M. W., \& Gaskell, G. (2008). Social representations theory: A progressive research programme for social psychology. Journal for the Theory of Social Behaviour, 38(4), 335-353. https://doi.org/10.1111/j.14685914.2008.00374.x

Bonetto, E. (2018). New Ideas in Psychology The fundamental needs underlying social representations. New Ideas in Psychology, 51(June), 40-43. https://doi.org/10.1016/j.newideapsych.2018.06.003

Castro, P. (2006). Applying social psychology to the study of environmental concern and environmental worldviews: contributions from the social representations approach. Journal of Community \& Applied Social Psychology, 16(4), 247-266. https://doi.org/10.1002/ casp. 864

Elcheroth, G., Doise, W., \& Reicher, S. (2011). On the knowledge of politics and the politics of knowledge: How a social representations approach helps us rethink the subject of political psychology. Political Psychology, 32(5), 729-758. https://doi.org/10.1111/j.14679221.2011.00834.x

Federico, N., Galli, I., Fasanelli, R., \& Schember, E. (2017). The construction of icons as a Ediciones EFIM means of access to the social representation of culture. Culture \& Psychology, 1-21. https:// doi.org/10.1177/1354067X17721860

Greenland, K., Andreouli, E., Augoustinos, M., \& Taulke-Johnson, R. (2018). What Constitutes 'Discrimination' in Everyday Talk? Argumentative Lines and the Social Representations of Discrimination. Journal of Language and Social Psychology, 1-21. https://doi. org/10.1177/0261927X18762588

Joffe, H. (2003). Risk: from perception to social representation. The British Journal of Social Psychology / the British Psychological Society, 42, 55-73. https://doi. org/10.1348/014466603763276126

Jung, Y., \& Pawlowski, S. D. (2014). Understanding consumption in social virtual worlds: A sensemaking perspective on the consumption of virtual goods. Journal of Business Research, 67(10), 2231-2238. https://doi.org/10.1016/j. jbusres.2014.01.002

Kadianaki, I., \& Andreouli, E. (2015). Essentialism in Social Representations of Citizenship : An Analysis of Greeks ' and Migrants ' Discourse, $\mathrm{xx}(\mathrm{xx}), 1-16$. https://doi.org/10.1111/ pops. 12271

Koshkin, A. P., Abramov, R. A., Rozhina, E. Y., \& Novikov, A. V. (2018). Role of Social Representations in Student Motivation for Acquiring Further Education. Interchange, 49(3), 313-341. https://doi.org/10.1007/s10780-0189328-3

Lai, P., Morrison-saunders, A., \& Grimstad, S. (2017). Operating small tourism fi rms in rural destinations : A social representations approach to examining how small tourism fi rms cope with non-tourism induced changes. Tourism Management, 58, 164-174. https://doi.org/10.1016/j. tourman.2016.10.017

Lelaurain, S., Fonte, D., Aim, M. A., Khatmi, N., Decarsin, T., Lo Monaco, G., \& Apostolidis, T. (2018). "One Doesn't Slap a Girl but..." Social Representations and Conditional Logics in Legitimization of Intimate Partner Violence. 
Sex Roles, 78(9-10), 637-652. https://doi. org/10.1007/s11199-017-0821-4

Levidow, L., \& Upham, P. (2017). Linking the multi-level perspective with social representations theory: Gasifiers as a niche innovation reinforcing the energy-from-waste (EfW) regime. Technological Forecasting and Social Change, 120, 1-13. https://doi.org/10.1016/j. techfore.2017.03.028

Licata, L., Khan, S. S., Lastrego, S., Cabecinhas, R., Pires, J., \& Liu, J. H. (2017). International Journal of Intercultural Relations Social representations of colonialism in Africa and in Europe : Structure and relevance for contemporary intergroup relations. International Journal of Intercultural Relations, (November 2016), 0-1. https://doi.org/10.1016/j.ijintrel.2017.05.004

Liu, J. H., \& Hilton, D. J. (2005). Copyright (C) The British Psychological Society How the past weighs on the present : Social representations of history and their role in identity politics Copyright (C) The British Psychological Society. British Journal of Social Psychology, 44, 537-556. https://doi.org/10.1348/014466605X27162

Moloney, G., Hayman, J., Gamble, M., Smith, G., \& Hall, R. (2017). Translation strategies, contradiction, and the theory of social representations: Why discussing needles may improve blood donor retention. British Journal of Social Psychology, 56(2), 393-415. https://doi. org/10.1111/bjso. 12187

Mora, M. (2002). La teoría de las representaciones sociales de Serge Moscovici. Athenea Digital, (2), 1-25. https://doi.org/10.5565/rev/ athenead/v1n2.55

Penz, E., \& Sinkovics, R. R. (2013). Triangulating consumers ' perceptions of payment systems by using social representations theory : A multi-method approach, 306(May), 293-306. https://doi.org/10.1002/cb

Rosa, A. S. de, Bocci, E., \& Picone, M. (2018). E- Branding and Institutional Web Sites: The "Visiting Card" of the Municipalities of Rome and Paris. Science and Engineering Indicators 2018. https://doi.org/10.1002/ejoc.201200111
Schultes, A. M., Kollmayer, M., Mejeh, M., \& Spiel, C. (2018). Attitudes toward evaluation: An exploratory study of students' and stakeholders' social representations. Evaluation and Program Planning. https://doi.org/10.1016/j. evalprogplan.2018.06.002

Visconti, L. M. (2016). A conversational approach to consumer vulnerability: performativity, representations, and storytelling. Journal of Marketing Management, 32(3-4), 371-385. https://doi.org/10.1080/0267257X.2015.1122660 